\title{
Extended Spectrum Beta-Lactamase Producing Bacteria in Waste Water Alexandria, Egypt
}

\author{
Amira Ezzat Khamis Amine
}

\begin{abstract}
Waste water is a reservoir of resistant bacteria and an excellent location to describe the pattern of fecal carriage of extended-spectrum $\beta$ lactamases (ESBLs) producing bacteria in the community. In this study, the aim was to determine the proportion of ESBL producing Gram-negative bacteria in waste water. Also to describe the antimicrobial susceptibility and types of beta-lactamases (TEM, SHV and CTX-M) among $E$. coli and $K$. pneumoniae isolates from waste water in the city of Alexandria, Egypt. The ESBLs compromised $69.8 \%$ in influent sewage and $57.7 \%$ in effluent sewage of the total Gram negative bacteria. The most frequently detected gene among $E$. coliisolates while $b l a_{\text {TEM }}$, while the most common among $K$. pneumonia isolates was $b a_{\mathrm{SHV}}$.
\end{abstract}

Index Terms-Antibiotic resistance, Egypt, ESBL, sewage.

\section{INTRODUCTION}

Waste water is a reservoir of resistant bacteria carried by the general population in the community. It carries the resistant bacteria introduced into the sewage system that come from human excretions (hospital and municipal effluent) as well as from animal husbandry [1]-[5].

Although other bacteria are more abundant, in the human intestine, faecal coliforms including Escherichia coli (E. coli) andKlebsiellapneumoniae (K. pneumoniae) are more detected in the environment because of the faster die-off of other enteric bacteria [6]-[8]. Extended-spectrum $\beta$ lactamases (ESBLs) producing bacteria are a group of emerging resistant bacteria that is on the increase globally causing a major public health problem [9]. ESBLs enzymes have the ability to hydrolyze and cause resistance to newer $\beta$-lactam antibiotics, including the third-generation cephalosporins and monobactams. They are classified into four molecular classes A through D according to the primary structure of the $\beta$-lactam enzyme that they produce.ESBL-producing E. coli and K. pneumoniae belong [9] to class A $\beta$ lactamases and has three major groups TEM, SHV, and CTX-M types that are most commonly detected in clinical isolates [10]. ESBL-producing $E$. coli and $K$. pneumoniae are now listed as one of the six drug-resistant pathogens for which few potentially effective drugs are available [11].

ESBLs producing bacteria can spread through the community through fecal carriage, which is a key epidemiological factor in its spread. Intestinal carriage has been widely described in hospitalized patients and in the general healthy population [12], [13]. Studies have shown an alarming rate of carriage of ESBLs producing bacteria in the

Manuscript received May 10, 2013; revised July 12, 2013.

Amira Ezzat Khamis Amine is with the High Institute of Public Health, Alexandria, Egypt (e-mail: amiraamine@gmail.com). community both in industrialized and developing countries [13]-[15]. Also, very few studies have been done to describe the presence of these resistant bacteria in environmental samples especially in waste water [16], [17].

Dissemination of ESBLs producing genes can occur through horizontal gene transfer from resistant pathogens in waste water to environmental nonpathogenic bacteria [18]-[20]. Environmental non-pathogenic bacteria would then serve as a reservoir of resistance genes [21]. The risk of contamination is greatest when wastewater is discharged directly into the environment [22].

Data is very scarce about the prevalence of ESBL resistant genes in Egypt especially in a community based settings, and antimicrobial resistance patterns of bacteria in wastewater is largely unknown [23]. A study conducted in Sweden found the carriage of ESBLs among patients with travellers' diarrhea returning from Egypt to be $50 \%$ [24].

Sewage is an excellent location to describe the pattern of fecal carriage of ESBLs producing bacteria in the community. In this study, the aim was to determine proportion of ESBL producing Gram-negative bacteria in waste water. Also to describe the antimicrobial susceptibility and types of beta-lactamases (TEM, SHV and CTX-M) among E. coliand $K$. pneumoniae isolates from waste water in the city of Alexandria, Egypt.

\section{MATERIALS AND METHODS}

\section{A. Wastewater Sampling}

Wastewater samples were collected from a sewage treatment plant (A) in the city of Alexandria, Egypt.The plant is a primary treatment facility that receives an average of $800,000 \mathrm{~m}^{3}$ per day. Sewage in the plant is predominantly municipal but also receives wastewater from hospitals and industrial plants.

In the period between December 2012 and April 2013, sampling was performed five times. Each time, 2 samples were collected, one from influent waste water (raw sewage) going into the treatment plant and the other one from the effluent waste water after treatment.

\section{B. Determination of Bacterial Count and Identification of Isolates}

The sewage samples were collected using sterile bottles. For quantitative analysis, a series of decimal dilutions $\left(10^{1}\right.$, $10^{2}, 10^{3}$ and $10^{4}$ ) was prepared starting with $1 \mathrm{ml}$ of sewage samples diluted in $9 \mathrm{ml}$ of saline solution $(0.9 \% \mathrm{NaCl})$. A volume of 100ul from each well homogenized dilution was inoculated onto the culture media. Each dilution was inoculated into each of MacConkey agar (Oxoid) and MacConkey agar supplied with $2 \mathrm{ug} / \mathrm{ml}$ ceftazidime (Oxoid, 
Sigma).Plates were incubated at $37{ }^{\circ} \mathrm{C}$ for 24 hours after inoculation.Following incubation, colonies on each plate were counted.

Colonies suspected to be EBLs producing E. coli or $K$. pneumonia were picked up from MacConkey agar supplied with $2 \mathrm{ug} / \mathrm{ml}$ ceftazidime. The lactose fermenting colonies were subcultured and identified based on the following biochemical tests: oxidase, catalse, indole, methyl red, Voges-Proskauer, citrate utilization, triple sugar iron following the guidelines inBailey and Scott's Diagnostic Microbiology [25].

\section{Antimicrobial Susceptibility Testing}

Verification of the ESBL-producing phenotype of identified colonies was confirmed by the combination disk method described by the Clinical Laboratory Standard Institute (CLSI). The test was performed using both the antibiotics (oxoid) cefepime $(30 \mu \mathrm{g})$ and cefotaxime $(30 \mu \mathrm{g})$ alone and in combination with an inhibitor (cefepime-clavulanic acid $30 / 10 \quad \mu \mathrm{g} \quad$ and cefotaxime-clavulanic acid 30/10 $\mu \mathrm{g}$ ). ESBL production was considered positive when $\mathrm{a} \geq 5$-mm increase in the zone diameter for the betalactam agent tested in combination with clavulanic acid versus its zone when tested alone [26].

Identified strains were also screened for their antimicrobial susceptibility to other antibiotics using single disc diffusion method described by Bauer et al. [27]. The selected antibiotic discs were: amoxicillin-clavulanic acid (20/10 $\mu \mathrm{g})$, piperacillin tazobactam $(100 / 10 \mathrm{ug}), \quad$ trimethoprim sulphametoxazole $(1.25 / 23.75 \mu \mathrm{g})$, ciprofloxacin (5 ug), gentamicin (10 ug), tobramycin(10 ug), chloramphenicol (30 $\mu \mathrm{g})$ and the carbapenemes: meropenem $(10 \mathrm{ug})$, imipenem (10 ug), etrapenem (10 ug ). Inhibition zones were measured and break points used to categorize isolates as resistant or susceptible for each antimicrobial agent were decided according to CLSI guidelines [26].

\section{Detection of ESBLsEncoding Genes}

All identified E. coli and K. pneumoniawere tested for the presence of $b l a_{\mathrm{TEM}} b l a_{\mathrm{SHV}}$ and $b l a_{\mathrm{CTX} \text {-M }}$ genes using multiplex PCR assay. DNA was extracted from fresh culture by boiling for five minutes. The supernatant was used as a source of template for amplification.

Beta-lactamases were detected using the primers; TEM-F (5 GTG CGG TAT TAT CCC GTG TT 3), TEM-R (5 AAC TTT ATC CGC CTC CAT CC 3), SHV-F (5 GGA AAC GGA ACT GAA TGA GG 3), SHV-R (5 ATC CCG CAG ATA AAT CAC CA 3), CTX-M-F (5 CGC TTT CCA ATG TGC AGT AC -3) and CTX-M-R (5 TCG CCG CTG CCG GTC TTA TC 3). Amplification was performed using the following temperature profile: initial denaturation ( $94 \mathrm{C}$ for 5 $\mathrm{min})$; 30 cycles of denaturation $\left(94^{\circ} \mathrm{C}\right.$ for $\left.30 \mathrm{~s}\right)$, annealing $\left(58^{\circ} \mathrm{C}\right.$ for $\left.1 \mathrm{~min}\right)$ and polymerization $\left(72^{\circ} \mathrm{C}\right.$ for $\left.1 \mathrm{~min}\right)$; and an additional polymerization step $\left(72{ }^{\circ} \mathrm{C}\right.$ for $\left.7 \mathrm{~min}\right)$. The amplification products were analyzed by agarose gel electrophoresis [28].

\section{RESULTS}

The total count of Gram negative bacilli on MacConkey agar and total count of ESBLs producing Gram negative bacilli on MacConkey agar supplied with ceftazidime were compared. The difference is summarized in Table I. The mean of both counts was slightly higher in influent than effluent flow. The percentage of ESBLs producing bacteria to the total count was $69.8 \%$ in influent waste water while it was $57.7 \%$ in effluent waste water.

TABLE I: COLONY FORMING UNIT COUNT OF GRAM NEGATIVE BACILLI

\begin{tabular}{|l|l|l|l|l|l|l|}
\hline \multirow{2}{*}{ Type } & \multicolumn{4}{|l|}{ Influent waste water } & \multicolumn{3}{l|}{ Effluent waste water } \\
\cline { 2 - 7 } & Max & Min & Mean & Max & Min & Mean \\
\hline Gram negative bacilli & $9.7 \times 10^{5}$ & $1.5 \times 10^{5}$ & $5.2 \times 10^{5}$ & $9 \times 10^{5}$ & $1.01 \times 10^{5}$ & $5.03 \times 10^{5}$ \\
\hline $\begin{array}{l}\text { ESBLs producing Gram } \\
\text { negative bacilli }\end{array}$ & $7 \times 10^{5}$ & $1.56 \times 10^{5}$ & $3.63 \times 10^{5}$ & $4.5 \times 10^{5}$ & $1.7 \times 10^{5}$ & $2.9 \times 10^{5}$ \\
\hline
\end{tabular}

TABLE II: ANTIMICROBIAL RESISTANCE AMONG ESBL PRODUCING ISOLATES

\begin{tabular}{|c|c|c|c|c|c|c|c|c|c|c|}
\hline \multirow[t]{2}{*}{ Type of sample } & \multicolumn{10}{|c|}{ Antimicrobials } \\
\hline & AMC & TZP & SXT & TOB & GEN & $\mathrm{C}$ & ETP & $\operatorname{MEM}(\%)$ & IPM (\%) & CIP (\%) \\
\hline $\begin{array}{c}\text { Influent waste } \\
\text { water }\end{array}$ & $30(76.9)$ & $29(74.3)$ & $30(76.9)$ & $17(43.6)$ & $15(38.4)$ & $8(20.5)$ & $24(61.5)$ & $2(5.1)$ & $4(10.2)$ & $28(71.7)$ \\
\hline $\begin{array}{c}\text { Effluent waste } \\
\text { water }\end{array}$ & $34(70.8)$ & $31(64.5)$ & $41(85.4)$ & $28(58.3)$ & $4(50)$ & $14(25)$ & $32(66.6)$ & $0(0)$ & $4(8.3)$ & $31(64.5)$ \\
\hline
\end{tabular}

AMC, Amoxicillin-clavulanic acid; C, Chloramphenicol; ETP, Ertapenem; GEN, Gentamicin; IPM, Imipenem; MEM, Meropenem; TZP,

Piperacillin-tazobactam; TOB, Tobramycin; SXT, Trimethoprim-sulfamethoxazole; CIP, ciprofloxacin

A total of 87 EBLs producing $E$. coli (74 isolates) and $K$. pneumonia (13 isolates) were identified using established biochemical and the antimicrobial resistance patterns of these isolates are shown in Table II.

The bacterial isolates showed highest antimicrobial resistance rates to amoxicillin-clavulanic acid, piperacillin-tazobactam and trimethoprim/sulfamethoxazole. The resistance rate was also high for ciprofloxacin and ertapenem. Considering the presence of antimicrobial resistance in the different samples, the resistance was higher among isolates from influent waste water to amoxicillin-clavulanic acid, piperacillin-tazobactam, meropenem, imipenemandciprofloxacin.

The distribution of the detected $b l a_{\mathrm{TEM}}, b l a_{\mathrm{SHV}}$ and bla $a_{\mathrm{CTX}}-\mathrm{M}$ genes is summarized in Table III. In most isolates, a single resistance gene was detected with a smaller number of isolates harboring 2 or 3 genes. The most frequently detected gene among $E$. coli was bla $a_{\mathrm{TEM}}$ either found alone or in association with another gene, while the most common in $K$. pneumonia was $b l a_{\mathrm{SHV}}$ also alone or in combinaton. The association between TEM and SHV was also the most frequent. In $5.4 \%$ of $E$. coli and $7.7 \%$ of $K$. pneumoniano 
resistance genes were detected.

TABLE III: FREQUENCY OF ESBLS GENES DETECTED IN BACTERIAL ISOLATES

\begin{tabular}{|l|c|c|}
\hline ESBLs genes & $\begin{array}{c}\text { E. coli } \\
\text { Number of isolates } \\
(\%)\end{array}$ & $\begin{array}{c}\text { K. pneumonia } \\
\text { Number of } \\
\text { isolates }(\%)\end{array}$ \\
\hline bla $_{\mathrm{TEM}}$ & $52(70.2)$ & 0 \\
bla $_{\mathrm{SHV}}$ & $5(6.8)$ & $6(46.1)$ \\
bla $_{\mathrm{CTX}-\mathrm{M}}$ & $1(1.4)$ & 0 \\
bla $_{\mathrm{TEM}}$, bla $_{\mathrm{SHV}}$ & $8(10.8)$ & $5(38.5)$ \\
bla $_{\mathrm{CTX}-\mathrm{M}}$, bla $_{\mathrm{TEM}}$ & $3(4)$ & $1(7.7)$ \\
bla $_{\mathrm{CTX}-\mathrm{M}}$, bla $_{\mathrm{SHV}}$, bla $_{\mathrm{TEM}}$ & $1(1.4)$ & 0 \\
Non-detected & $4(5.4)$ & $1(7.7)$ \\
Total & $74(100)$ & $13(100)$ \\
\hline
\end{tabular}

\section{DISCUSSION}

The increase of ESBL-producing pathogens recently is posing a serious public health problem. Few studies have been reported on the antimicrobial resistance patterns of environmental strains of bacteria in Egypt. The main focus of research has been primarily on clinical isolates, and there are no previous reports of the extent of presence of resistant bacteria in sewage in Egypt.

In this study, we compared the count of ESBLs producing bacteria to the total count of Gram negative bacteria in sewage. The ESBLs compromised $69.8 \%$ in influent sewage and $57.7 \%$ in effluent sewage of the total Gram negative bacteria. A lower percentage is reported by Chagas et al., who showed that $40 \%$ of isolates from sewage were characterized as ESBL producers [29]. Also, according to Prado et al., $33 \%$ to $53 \%$ of $K$. pneumoniae isolates in sewage were ESBL producers [30]. The higher proportion of resistance in Egyptian sewage might be explained by the high antimicrobial prescription rates with low rates of appropriateness of antibiotic prescription reported in Egypt, where the most of prescribed antimicrobial agents belong to cephalosporins and penicillins classes [31]. This non-regulated, high use of antibiotics is expected to favor selection for resistant bacteria and increase fecal carriage of resistant bacteria by the general population.

Isolates also showed a high percentage of resistance to antibiotics especially amoxicillin-clavulanic acid, piperacillin-tazobactam, trimethoprim-sulfamethoxazole and ciprofloxacin. Prado et al reported a lower percentage of resistance to these antibiotics amongESBL $K$. pneumoniae isolated from sewage [30]. Isolates showed an alarming high resistance to ertapenem(61.5-66\%) compared to reported resistance globally [32]-[33], since carbapenems are the treatment of choice for ESBL producing bacteria.

Sewage serves as a pool of resistant bacteria that reflects the composition of bacterial clones carried by the general population. In Egypt, little is known about the genetic makeup of ESBLs. In this study, TEM enzyme was the most prevalent type among E. coli $(70.2 \%)$ while SHV was predominant among K. pneumoniae $(40.1 \%)$ isolates. Ahmed et al reported that SHV was also the predominant type $(61.1 \%)$ of ESBL enzymes among $K$. pneumoniae isolated from clinical samples [34]. TEM is also reported to be the most prevalent among E. coli isolates, but while CTX-M was found in a small number of isolates in this study, previous reports have indicated its prevalence is on the increase in Egypt [35], [36]. These results suggest that the prevalent type in this study of is similar to the few reports that described the prevalent genes in clinical samples. Clinical isolates may be virulent variants of ESBL producing $E$. coli, and $K$. pneumoniae associated with gastrointestinal colonization in humans.

Studies have shown that plasmids can carry more than one gene that expresses ESBL resistance and may be responsible for high level ESBL resistance phenotypes. Some isolates in this study carried more than one ESBL resistance enzymes, and the association between types TEM and SHV was more frequent. On the contrary, five isolates did not carry any of the genes detected, suggesting other genes responsible for resistance [17].

ESBL producing bacteria pose a potential risk of dissemination of their genes to the environment causing possible human exposure and subsequent infection. This has not been confirmed as studies of ESBL genes in wastewater have only been directed at detection of its presence and description of its genetic background and a direct link between the presence of resistant bacteria in waste water and the dissemination of antimicrobial resistance has not been established [4]-[30]. In Egypt more than half the population does not have access to waste water treatment facilities. The major treatment plants in Alexandria, Egypt have only primary treatment facilities and waste water is dispersed into the environment. There is now also the increasing practice of the reuse of waste water in irrigation of agricultural land and the possible use of sewage sludge [37], [38]. With the presence of high proportion of resistant bacteria in sewage, more efforts are required for elimination of resistant bacteria from waste water before its release in the environment or its reuse for agricultural purposes. Also more studies are required to assess the risk of waste water disposal and reuse in environmental contamination.

\section{CONCLUSION}

In conclusion, it is shown in this study that antibiotic-resistant ESBL producing bacteria make up more than half the Gram negative bacilli found in sewage at the end of waste water purification process, posing a risk of its spread to the environment and subsequent human and animal exposure.

\section{REFERENCES}

[1] X. X. Zhang, T. Zhang, and H.H.Fang, "Antibiotic resistance genes in water environment," Appl. Microbiol. Biotechnol, vol. 82, no. 3, pp. 397-414, 2009.

[2] T. Tennstedt, R. Szczepanowski, S. Braun, A. Puhler, and A. Schluter, "Occurrence of integron-associated resistance gene cassettes located on antibiotic resistance plasmids isolated from a wastewater treatment plant," FEMS MicrobiolEcol, vol. 45, no. 3, pp. 239-252, 2003.

[3] R. J. Mesa et al., "Extended-spectrum beta-lactamase-producing Enterobacteriaceae in different environments (humans, food, animal farms and sewage)," J. Antimicrob Chemother, vol. 58, no. 1, pp. 211-215, 2006.

[4] C. Monaghan and E. Colleran, "Antibiotic resistance of faecal coliforms in hospital and city sewage in Galway," Ir J Med Sci., vol. 150 , no. 10 , pp. 304-309, 1981 .

[5] N. Esiobu, L. Armenta, and J. Ike, "Antibiotic resistance in soil and water environments," Int J Environ Health Res, vol. 12, no. 2, pp. 133-144, 2002.

[6] X. Bonjoch, E. Balleste, and A. R. Blanch, "Enumeration of bifidobacterial populations with selective media to determine the 
source of waterborne fecal pollution," Water Res., vol. 39, no. 8, pp. 1621-1627, 2005.

[7] X. Bonjoch, F. Lucena, and A. R. Blanch, "The persistence of bifidobacteria populations in a river measured by molecular and culture techniques," J. Appl. Microbiol, vol. 107, no. 4, pp. 1178-1185, 2009.

[8] J. R. Ottoson, "Bifidobacterial survival in surface water and implications for microbial source tracking," Can J. Microbiol, vol. 55 no. 6, pp. 642-647, 2009

[9] R. P. Ambler, "The structure of beta-lactamases," Philos Trans R Soc Lond B Biol Sci, vol. 289, no. 1036, pp. 321-331, 1980.

[10] R. Canton et al., "Prevalence and spread of extended-spectrum beta-lactamase-producing Enterobacteriaceae in Europe," Clin Microbiol Infect, vol. 14, Suppl. 1, pp. 144-153, 2008.

[11] G. H. Talbot, J. Bradley, J. E. Edwards, Jr., D. Gilbert, M. Scheld, and J. G. Bartlett, "Bad bugs need drugs: an update on the development pipeline from the Antimicrobial Availability Task Force of the Infectious Diseases Society of America," Clin Infect Dis., vol. 42, no. 5 , pp. 657-668, 2006.

[12] K. P. Abhilash, B. Veeraraghavan, and O. C. Abraham, "Epidemiology and outcome of bacteremia caused by extended spectrum beta-lactamase (ESBL)-producing Escherichia coli and Klebsiella spp. in a tertiary care teaching hospital in south India," J. Assoc Physicians India, vol. 58, pp. 13-17, 2010.

[13] P. Herindrainy et al., "Rectal carriage of extended-spectrum beta-lactamase-producing gram-negative bacilli in community settings in Madagascar," PLoS One, vol. 6, no. 7, pp. e22738, 2011.

[14] J. D. Pitout and K. B. Laupland, "Extended-spectrum beta-lactamase-producing Enterobacteriaceae: an emerging public-health concern," Lancet Infect Dis., vol. 8, no. 3, pp. 159-166, 2008.

[15] T. M. Coque, F. Baquero, and R. Canton, "Increasing prevalence of ESBL-producing Enterobacteriaceae in Europe,” Euro Surveill, vol. 13 no. 47,2008

[16] T. R. Walsh, "Emerging carbapenemases: a global perspective," Int J Antimicrob Agents, vol. 36 Suppl. 3, pp. S8-14, 2010.

[17] Y. Pfeifer, A. Cullik, and W. Witte, "Resistance to cephalosporins and carbapenems in Gram-negative bacterial pathogens," International Journal of Medical Microbiology, vol. 300, no. 6, pp. 371-379, 2010.

[18] G. D. Wright, "Q\&A: Antibiotic resistance: where does it come from and what can we do about it?," BMC Biol., vol. 8, pp. 123, 2010.

[19] J. B. Bell, G. E. Elliott, and D. W. Smith, "Influence of sewage treatment and urbanization on selection of multiple resistance in fecal coliform populations," Appl Environ Microbiol, vol. 46, no. 1, pp. 227-232, 1983.

[20] G. R. Finch and D. W. Smith, "The survival of antibiotic - resistant escherichia coli in an activated sludge plant," Environmental Technology Letters, vol. 7, no. 1-12, pp. 487-494, 1986.

[21] F. Baquero, J. L. Martinez, and R. Canton, "Antibiotics and antibiotic resistance in water environments," Curr Opin Biotechnol, vol. 19, no. 3, pp. 260-265, 2008.

[22] S. Galvin, F. Boyle, P. Hickey, A. Vellinga, D. Morris, and M. Cormican, "Enumeration and characterization of antimicrobial-resistant Escherichia coli bacteria in effluent from municipal, hospital, and secondary treatment facility sources," Appl Environ Microbiol, vol. 76, no. 14, pp. 4772-4779, 2010.

[23] N. Fam et al., "CTX-M-15-ProducingEscherichia coliClinical Isolates in Cairo (Egypt), Including Isolates of Clonal Complex ST10 and Clones ST131, ST73, and ST405 in Both Community and Hospita Settings," Microbial Drug Resistance, vol. 17, no. 1, pp. 67-73, 2011.

[24] J. Tham, I. Odenholt, M. Walder, A. Brolund, J. Ahl, and E. Melander, "Extended-spectrum beta-lactamase-producing Escherichia coli in patients with travellers' diarrhoea," Scandinavian Journal of Infectious Diseases, vol. 42, no. 4, pp. 275-280, 2010.

[25] B. Forbes, D. Sahm, and A. Weissfeld, Bailey and Scott's Diagnostic Microbiology, 10 ed., St Louis: Mosby, 1998.
[26] Performance standards for antimicrobial susceptibility testing Twenty-First international supplement M100-S21, January 2011, Clinical and Laboratory Standards Institute, Wayne, PA, USA.

[27] A. W. Bauer, W. M. Kirby, J. C. Sherris, and M. Turck, "Antibiotic susceptibility testing by a standardized single disk method," Tech Bull Regist Med Technol., vol. 36, no. 3, pp. 49-52, 1966.

[28] H. Rodriguez-Villalobos, V. Malaviolle, J. Frankard, R. de Mendonca C. Nonhoff, and M. J. Struelens, "In vitro activity of temocillin against extended spectrum beta-lactamase-producing Escherichia coli," Antimicrob Chemother, vol. 57, no. 4, pp. 771-774, 2006.

[29] T. P. Chagas, L. M. Seki, J. C. Cury, J. A. Oliveira, A. M. Davila, D. M Silva, et al., "Multiresistance, beta-lactamase-encoding genes and bacterial diversity in hospital wastewater in Rio de Janeiro, Brazil," $J$. Appl. Microbiol, vol. 111, no. 3, pp. 572-581, 2011.

[30] T. Prado, W. C. Pereira, D. M. Silva, L. M. Seki, A. P. Carvalho, and M. D. Asensi, "Detection of extended-spectrum beta-lactamase-producing Klebsiella pneumoniae in effluents and sludge of a hospital sewage treatment plant," Lett. Appl. Microbiol, vol. 46, no. 1, pp. 136-141, 2008.

[31] M. A. Borg, P. Zarb, M. Ferech, and H. Goossens, “Antibiotic consumption in southern and eastern Mediterranean hospitals: results from the ARMed project," J. Antimicrob Chemother, vol. 62, no. 4, pp 830-836, 2008

[32] B. N. Chaudhuri et al., "Incidence of ESBL producers amongst Gram-negative bacilli isolated from intra-abdominal infections across India (based on SMART study, 2007 data)," J. Assoc Physicians India, vol. 59, pp. 287-292, 2011

[33] R. E. Badal, S. K. Bouchillon, S. H. Lob, M. A. Hackel, S. Hawser, and D. J. Hoban, "Etiology, Extended-Spectrum Beta-Lactamase Rates, and Antimicrobial Susceptibility of Gram-negative Bacilli Causing Intra-abdominal Infections in Patients in General Pediatric and Pediatric Intensive Care Units - Global Data from The Study for Monitoring Antimicrobial Resistance Trends (SMART) 2008-2010,' Pediatr Infect Dis J., 2013.

[34] S. H. Ahmed, E. A. Daef, M. S. Badary, M. A. Mahmoud, and A. A. Abd-Elsayed, "Nosocomial blood stream infection in intensive care units at Assiut University Hospitals (Upper Egypt) with special reference to extended spectrum beta-lactamase producing organisms," BMC Res Notes, vol. 2, pp. 76, 2009.

[35] M. H. Mohamed Al-Agamy, M. S. El-Din Ashour, and I. Wiegand, "First description of CTX-M beta-lactamase-producing clinical Escherichia coli isolates from Egypt," Int J Antimicrob Agents, vol. 27, no. 6 , pp. 545-548, 2006

[36] N. Fam et al., "CTX-M-15-producing Escherichia coli clinical isolates in Cairo (Egypt), including isolates of clonal complex ST10 and clones ST131, ST73, and ST405 in both community and hospital settings," Microb Drug Resist, vol. 17, no. 1, pp. 67-73, 2011.

[37] M. Ghazy, T. Dockhorn, and N. Dichtl, "Sewage Sludge Management in Egypt: Current Status and Perspectives towards a Sustainable Agricultural Use," World Academy of Science, Engineering and Technology, vol. no. 33, pp. 299-307, 2009.

[38] R. A. Wahaab and M. E.-D. Omar. Wastewater Reuse in Egypt: Opportunities and Challenges. [Online]. Available: http://www.waset.org/journals/waset/v33/v33-88.pdf.

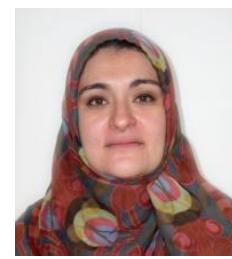

Amira E. K. Amine was born on $27^{\text {th }}$ April 1976 in Alexandria, Egypt. In 2000, she graduated from Faculty of Medicine, Alexandria University. She obtained her Ph.D. from the High Institute of Public Health, University of Alexandria, Egypt. She worked as a post doctoral researcher in Uppsala University, Sweden from 2009-2011. She is currently working as a lecturer of Microbiology at the High Institute of Public Health, University of Alexandria, Egypt. Her major field of study is public health microbiology. 